Winter 2018

\title{
Undergraduate Rehabilitation Education and Accreditation: The Importance of Being Persistent
}

\author{
David C. Perry \\ University of North Dakota, david.perry@UND.edu \\ Chrisann Schiro-Geist \\ Michelle Marme \\ J. Chad Duncan \\ Regina Robertson
}

See next page for additional authors

How does access to this work benefit you? Let us know!

Follow this and additional works at: https://commons.und.edu/ehb-fac

Part of the Health and Physical Education Commons

\section{Recommended Citation}

David C. Perry, Chrisann Schiro-Geist, Michelle Marme, et al.. "Undergraduate Rehabilitation Education and Accreditation: The Importance of Being Persistent" (2018). Education, Health \& Behavior Studies Faculty Publications. 33.

https://commons.und.edu/ehb-fac/33

This Article is brought to you for free and open access by the Department of Education, Health \& Behavior Studies at UND Scholarly Commons. It has been accepted for inclusion in Education, Health \& Behavior Studies Faculty Publications by an authorized administrator of UND Scholarly Commons. For more information, please contact und.commons@library.und.edu. 


\section{Authors}

David C. Perry, Chrisann Schiro-Geist, Michelle Marme, J. Chad Duncan, Regina Robertson, and Penny Willmering

This article is available at UND Scholarly Commons: https://commons.und.edu/ehb-fac/33 


\title{
Undergraduate Rehabilitation Education and Accreditation: The Importance of Being Persistent
}

\author{
David C. Perry, Chrisann Schiro-Geist, Michelle Marme, J. Chad Duncan, Regina Robertson, Penny \\ Willmering
}

\begin{abstract}
This article presents an overview of undergraduate rehabilitation education (URE) and the movement toward accreditation. Tracing the history of URE from the earliest days of rehabilitation education programs up to the present, this review discusses the purposes of URE, traditional URE program curricula, where URE graduates have been (and are being) employed, and the relationship between UREs and graduate rehabilitation counseling programs. The article also explains the development of URE curriculum and program standards, the development of a registry of qualified URE programs, and the transition to accreditation of URE programs in the United States. The purposes of accreditation are described, along with the advantages that accreditation offers to URE programs, their students, and to persons with disabilities.
\end{abstract}

Keywords: undergraduate rehabilitation education; bachelor's rehabilitation curricula; accreditation in rehabilitation education; rehabilitation career ladder; professional persistence

For the purposes of this discussion, we will begin with an overview of the history and evolution of undergraduate rehabilitation education (URE) in the United States. Next, we move into the reasons why accreditation of such programs is important, underscoring the impact it can have on universities, students, employers, and graduate rehabilitation education programs. Since there have been disagreements over the years about the relative value of URE accreditation, we present both sides of the advantages and disadvantages of the process. The article concludes with a discussion of the future outlook of URE accreditation, including the recent creation of a Committee on Rehabilitation Accreditation within the Commission on Accreditation of Allied Health Education Programs (CAAHEP).

\section{Early History of Undergraduate Rehabilitation Education}

In 1963, Hylbert stated, "Rehabilitation Education is an infant curriculum but, withal, a lusty infant. It no doubt will continue to be subject to careful examination, re-examination, and development for some time" (p. 24). From its beginning in the late 1950s, URE was conceptualized as an integration of disability awareness, community rehabilitation skills, applied psychology, and allied health coursework, all designed to prepare bachelor's-level students for professional careers in various allied health and human service fields. As seen within programs at institutions such as the Pennsylvania State University (PSU), the University of WisconsinStout (UW-S), Virginia Commonwealth University (VCU), and Syracuse University's Institute on Rehabilitation Education, rehabilitation education at the undergraduate level provided an interdisciplinary approach to professional training built on a strong liberal arts foundation.

Stegar (1974) believed that health and helping professions needed to join together to stop professional fragmentation and start a holistic approach to service delivery. This approach included new ways of gaining experience and training individuals at the community-practice level and university preprofessional level. Jacques (1972) stated that the field of rehabilitation must focus on preparation from a career ladder perspective, including professional rehabilitation preparation at all levels (bachelor's, master's, and doctoral). The push to have support personnel properly trained and educated was indicative of the initiatives being pursued. Jacques concluded that professions are not downgraded by different levels of training, but in fact, they make work more vital and helpful to society. 
To meet a void that was identified by the Pennsylvania Bureau of Vocational Rehabilitation and the State Office for the Blind, in 1957 PSU started an experimental URE program. At its inception, the Penn State curriculum was intended to serve as a foundation for graduate work in rehabilitation counseling. As the program evolved, however, the curriculum became broader and had more flexibility, making it appealing to students interested in directly entering the helping professions (Hylbert, 1963). The curriculum was seen as both a terminal degree in rehabilitation education and as a preparatory degree for graduate training.

This broadness and flexibility were viewed as a positive move for the educational experience of the student who was not forced to narrow their focus while taking classes, but rather to expand their possibilities in the area of health professions. Hylbert (1963) believed that rehabilitation professionals could work more effectively if they were part of an interdisciplinary team. Furthermore, as Hylbert stated, "It's reasonable to believe...(that) the attainment of mutual interdisciplinary respect and effective teamwork (are) made possible when a substantial portion of the educational experiences of all professionals represented in the field of rehabilitation becomes similar" (p. 24). Hylbert believed that this more liberal approach to training met the common preparatory goal for other health-related fields and any pre-professional program encompassing the field of rehabilitation (Duncan, 2008).

These insights regarding the development and foundation of a model curriculum for URE were put into place by Hylbert in 1957. The original program had students taking a minimum of 33 credit hours of electives, but strongly recommended 45 hours. For Hylbert and Kelz (1972), the core of the undergraduate rehabilitation curriculum consisted of a three-dimensional understanding of humanity focused on physical, social, and psychological factors. Hylbert and Kelz also recommended a substantial use of electives, arguing that this provided several advantages, such as:

- Extending the students' general or liberal education

- Providing the opportunity for wide exploration of multiple career choices

- Effectively meeting the entrance requirements to advanced study or specialization

- Increasing and broadening overall professional competencies

Another early pioneer of URE was the UW-S (known then as Stout University). In 1971, Henry Redkey referred to students who earned an undergraduate degree in rehabilitation studies at Stout University as rehabilitation generalists. Similar to Hylbert's conceptualization, Redkey contended that the rehabilitation generalist should have broad-based skills and information that would allow the graduate to either enter health-related fields or be a better fit for graduate-level rehabilitation training. Redkey's description of a rehabilitation generalist was "a person with a good basic grounding in rehabilitation and simple skills of counseling, evaluation, and the highly important (positive) attitudes toward disabled people" (1971, p. 26).

Similar to the Penn State program, Stout's program also had electives. However, the electives were more specifically related to rehabilitation and included such areas as industrial arts, home economics, and business administration. Unique to Stout was the experiential approach requiring students to engage in a full summer of an independent study or internship in a rehabilitation setting.

In 1974, VCU established a Baccalaureate Program in Rehabilitation Services that consisted of 33 semester hours of coursework in liberal arts and sciences, 15 hours of community and public affairs, a 12hour cognate in upper level social and behavioral sciences, and 33 semester hours of electives (Martin \& Gandy, 1985). The program provided a humanistic approach that incorporated a professional education foundation with a liberal arts perspective, while having a focus on providing a holistic view in working with individuals with various disabilities (Martin \& Gandy, 1985). The unique approach of VCU's 
program was that it provided students with the opportunity to obtain a specialization in alcoholism and drug rehabilitation (Martin \& Gandy, 1985).

Concurrently, a number of individuals from various human service-related fields came together at Syracuse University (1973) to create a multidisciplinary approach to the development of rehabilitation education curriculum guidelines. Feinberg, Sundblad, and Glick (1974) reported that the recommended curriculum would be delivered as "a series of educational experiences designed to provide the unique as well as the generic skills necessary for the effective functioning of the professional rehabilitation services advocate" (p. 11). Through various task groups, data were collected which related to core knowledge, attitudes, and skills that established specific curriculum guidelines; that is, core knowledge areas and core skill areas (Feinberg et al., 1974).

The PSU, Stout, and VCU programs, along with the multi-disciplinary approach of the Syracuse University Institute on Rehabilitation Education formed the foundation to what today is known as URE. These programs and individuals wisely did not narrow their perspectives of education and what an education can offer, but instead created a broad and flexible foundation that could be molded to meet the needs of any institution wanting to create an undergraduate degree in rehabilitation. The two common factors of all of these programs were (1) a holistic and humanistic approach toward humanity, and (2) learning how to effectively work with persons with disabilities (PWD).

\section{Purposes of Accreditation}

Accreditation is generally considered a positive achievement in the world of higher education. The Council for Higher Education Accreditation (CHEA) reports: "Accreditation is a review of the quality of higher education institutions and programs. In the United States, accreditation is a major way that students, families, government officials, and the press know that an institution or program provides a quality education" (CHEA, 2018, paragraph 1).

The authors of the current article have long argued that the accreditation of URE is desirable because it will improve the quality of these programs and provide a degree of accountability that would not otherwise exist. From our perspective, the advantages of URE accreditation can be divided into several categories: (a) advantages to universities and colleges, (b) advantages to students and their families, and (c) advantages to employers.

\section{Advantages of Accreditation to Universities/Colleges}

Colleges and universities offering accredited programs may experience several benefits in regard to student recruitment, quality assurance, and the support of external funding sources. For example, in an environment where there is greater competition for students, having programs that are accredited demonstrates a level of quality assurance that provides an advantage in recruiting students. Such accreditation indicates that the college or university values the quality of that program and is willing to invest in its on-going success. Another advantage is related to program evaluation. Institutions of higher learning are required by their regional accrediting bodies to periodically evaluate the effectiveness of their programs, with the goal of program improvement. For many universities and colleges, programs that are accredited do not complete these internal reviews, but instead can rely on the external review conducted by the professional accrediting body. This saves time and money for the host institution. Another advantage is related to external funding. Programs that are accredited may be more likely to experience success in seeking and receiving grant funds because funding sources have greater confidence in the quality of the program and its faculty. 


\section{Advantages to Students and Their Families}

Higher education is a major investment on the part of students and their families. Accredited programs are often perceived as a safer investment due to the quality and excellence that is indicated. In fact, accrediting bodies often require that recognized programs provide information to their consumers to help them make informed decisions. Clear and accessible information regarding such issues as graduation rates, employment rates of graduates, and starting salaries of their students clearly lends credibility to their degree (CF1EA, 2010). Family members have reason to believe that students are graduating from a recognized program that has met quality standards. Students graduating from accredited programs may also tend to identify more strongly with the profession represented by their degree.

\section{Advantages to Employers and Graduate Programs}

Employers are expected to assess the quality of a job applicant's preparation for a specific job and position. Knowing that a student has graduated from a high-quality undergraduate program, as demonstrated by fact that the program is accredited, may increase the confidence that the employer has made a good selection. Because accrediting bodies sometime require programs to have advisory councils that include employers and graduate educators, it may result in employers and graduate educators being more supportive of graduates of the accredited program.

Graduate rehabilitation counseling programs may also benefit because graduate educators can assume that graduates of accredited ERE programs have certain knowledge, skills, and attitudes that serve as a foundation for more advanced rehabilitation counselor training. For example, URE programs typically provide a basic understanding of the lived experience of disability, an appreciation of the organizational structure of human service and rehabilitation systems, an introduction to case management principles, and the importance of integration of PWD into all parts of the community. Not having to teach these fundamentals would allow graduate programs to focus on more in-depth aspects of rehabilitation counseling, such as counseling theories and techniques, adjustment to disabilities, psychological and vocational assessment, career counseling, the impact of disabilities on families, professionalism, and social change skills. Some graduate programs also offer accelerated graduate degrees for those students who can demonstrate they have already completed certain specific courses that are required in graduate programs.

\section{URE Accreditation: Point/Counterpoint}

While the need for URE accreditation seemed clear to many, the path to undergraduate accreditation has had its detractors. Opposing graduate educators emphasized that bachelors-level practitioners were not counselors and they might take away jobs from rehabilitation professionals with graduate degrees. Undergraduate educators countered that their graduates were filling important roles in community rehabilitation agencies and were clearly not being trained as counselors.

A great deal of rehabilitation literature illustrates these different viewpoints. For example, Szymanski, Mizelle, Tansey, Tschopp, and Willmering (2000) suggested that bachelor-level practitioners were not developmentally capable of adequately filling the complex professional roles required of those who work with PWD. These authors also worried that URE programs might duplicate the curriculum of master's rehabilitation counseling programs. However, early advocates for URE had called for a broad, liberal arts education which only emphasized a basic understanding of disability and helping skills (Gandy \& Martin, 1985). Supporters of URE contended that the goal of such programs was to prepare humane and sensitive professionals who could address the unmet need for service providers in community-based rehabilitation agencies (National Council on Rehabilitation Education, 1987; Muzzio, 2000). 
Szymanski et al. (2000) also suggested that there was a risk that bachelor-level practitioners would take away employment opportunities from master's trained rehabilitation counselors, although they provided no empirical evidence to justify this concern. In fact, they seemed to confuse the specific and well-defined role of "rehabilitation counselor" (see Berven, 1979; Leahy, Chan, \& Saunders, 2003) with the more generic and inclusive term "rehabilitation professional." By contrast, Williamson, Evenson, and Perry (1996) conducted a national study and found that while bachelor-level professionals provided a wide range of roles and competencies, their roles did not replace or replicate the role of the rehabilitation counselor.

This was especially evident in the survey data they provided from undergraduate rehabilitation educators. According to the rehabilitation administrators and educators they surveyed, the most appropriate roles for bachelor-level rehabilitation workers were those of case managers, assistants to counselors, and job placement specialists.

This was also seen in a second national survey completed by undergraduate rehabilitation program directors (Perry, 2000). While there were many distinct vocational roles for URE graduates, survey participants still supported requiring a graduate degree for rehabilitation counselors in both the public and private sectors. Another study completed by Evenson and Holloway (2000) reviewed specific competencies expected of baccalaureate-level rehabilitation workers and found that among workers and their supervisors, there were clearly defined and detailed levels of knowledge, skills, and attitudes expected of these workers. In addition, McAllan and Sales (2000) found that a bachelor's degree in rehabilitation provided access to a useful career ladder for workers in community rehabilitation agencies who wanted to advance in their rehabilitation careers. This career ladder was especially beneficial to practitioners who held minority or disability status. This study also indicated that individuals who were most likely to work directly, and often most intimately, with people who had disabilities and their families, frequently only had high school degrees.

Still, there were those who feared that if URE accreditation demonstrated that undergraduates were receiving a highquality rehabilitation education, employers might select these graduates instead of graduates of rehabilitation counseling master's programs. Although a major concern of those who argued that the pubic vocational rehabilitation system was better served by hiring Certified Rehabilitation Counselors who had master's degrees, the reality is that this issue is well beyond the control of accrediting bodies. For example, the Rehabilitation Act Amendments of 1992 required state Vocational Rehabilitation (VR) agencies to establish qualified personnel standards for VR counselors. Generally, this resulted in state agencies utilizing master's trained Certified Rehabilitation Counselors to provide services to their clients (Schroeder, 1998). Subsequently, the current Rehabilitation Act Amendments, passed in 2015, allow state VR agencies to develop personnel policies that result in hiring qualified staff who have the "attainment of a baccalaureate degree in a field of study reasonably related to vocational rehabilitation ... such as vocational rehabilitation counseling, social work, psychology, disability studies, business administration, human resources, special education, supported employment, customized employment, economics, or another field that reasonably prepares individuals to work with consumers and employers" (p. 38). This major departure from earlier legislation occurred without any reference to accreditation of URE programs or any requirement that VR counselors have recognized professional credentials. It is understandable that this legitimate concern has often fueled the controversy regarding URE accreditation.

Despite the misunderstandings, miscommunications, and conflicts that accompanied the efforts of undergraduate rehabilitation educators to move toward accreditation, their unifying goal was to enhance the services provided to PWD. Achieving a credible, thoughtful, and meaningful accreditation process was what they hoped would ensure that outcome. 


\section{Stages of Change in URE Accreditation}

In many ways, the movement toward accreditation of URE programs has followed the theoretical model of how change occurs in all important life decisions (Prochaska \& DiClementi, 1983). These stages include pre-contemplation, contemplation, preparation, action, and maintenance (including perhaps a "relapse" period). If there is a relapse, there can also be a resurrection toward a better, more positive change.

\section{Stage 1-The Pre-Contemplation Stage}

Accreditation in the field of rehabilitation education began in the 1970s with the creation of the Council on Rehabilitation Education (CORE). CORE was originally created as a consortium of various stakeholders in the profession of rehabilitation. Supported at the outset by the Rehabilitation Services Administration (RSA) through a grant to the University of Wisconsin-Madison, and then through funding to CORE itself, the model originally called for an umbrella paradigm which would allow for commissions in URE, graduate rehabilitation counselor education, vocational evaluation education, and education programs in rehabilitation administration.

The CORE Board made the decision to initiate the accreditation process by focusing on rehabilitation counselor education programs. However, as early as 1978, a group of undergraduate educators sent a letter to the CORE Board asking for a Commission under the CORE umbrella. During those early years, there was discussion at each CORE meeting about expanding accreditation into other areas of rehabilitation education. In fact, a group of educators from Southern Illinois University did move forward to generate accreditation standards for rehabilitation administration, but that effort was aborted by the untimely death of the major proponents of the movement. Meanwhile, during the first decade of its existence, CORE accredited over 100 rehabilitation counseling education programs.

\section{Stage 2-The Contemplation Stage}

During the 1980s, thanks in part to RSA grant funding of URE training programs, programs grew in number and in size. In an effort to be more inclusive of education at various levels, the Council on Rehabilitation Counselor Educators (CRCE) changed its name to the National Council on Rehabilitation Education (NCRE). In 1984, NCRE established a national committee to study the nature of URE in the United States. The committee developed a policy statement on URE which was approved by the NCRE Board in 1986. According to the policy statement, "the ideal purpose of a baccalaureate in rehabilitation services education can best be described as providing the student with a broad, liberal arts education combined with a basic understanding of physical, mental, emotional, and social disabilities" (p. 1). The study also suggested that there were three positive outcomes for graduates of such programs: (1) employment in rehabilitation-related, human services positions; (2) graduate study in rehabilitation counseling or allied health fields; and (3) employment or graduate study in other career areas that emphasize human relations or interpersonal skills.

Building on this greater acceptance of URE, a number of individuals began advocating for accreditation of such programs. In the late 1980s, advocates for URE attended annual CORE meetings to promote a Commission on Undergraduate Education, under the CORE umbrella. Gradually, others joined these early advocates to press the case for URE accreditation to CORE'S Board at their annual meetings.

\section{Stage 3-The Preparation Stage}

After years of advocacy, CORE officially established a study group to develop a plan for moving toward undergraduate accreditation in 1992. This led in 1998, to the CORE Board formally appointed a 
Committee on Undergraduate Education (CUE). This group developed the initial curriculum and program standards for URE, based on a role and function study of graduates of bachelor's rehabilitation programs (Herbert, Barrett, Evenson, \& Jacob, 2010).

In recognition of the challenges and complexities of accreditation at the undergraduate level, the CORE Board approved the development of a Registry of Undergraduate Rehabilitation Education Programs with CUE overseeing the process of determining program eligibility for the Registry, including the identification of required curriculum and program standards, along with requirements for faculty teaching in these programs.

As a result of the committee's work, the Registry of Undergraduate Programs in Rehabilitation and Disability Studies was established in 1998 with the first universities approved for the Registry in 1998. There was a clear intent that the Registry was to be different from accreditation as stated in the Application for the Registry, "The Registry process has been designed to avoid the appearance of a direct parallel to an accreditation process" (unpublished document, CORE, 1998). On the other hand, it was clearly CORE'S intent to develop a set of standards that could provide a beginning level of recognition for undergraduate rehabilitation programs.

Curriculum content areas were identified and developed using data-driven research from the undergraduate role and function study of Herbert et al. (2010), with input from interested university faculty and service delivery systems. University and faculty eligibility criteria were also developed with an appreciation of the vast diversity of undergraduate rehabilitation programs. These standards were developed to provide not only a sense of essential core disability and rehabilitation content areas, but also to meet the needs of PWD in the local communities where the universities were located. Core content areas included issues faced by persons experiencing disability, the rehabilitation delivery system, vocational rehabilitation outcomes, interpersonal communication skills, consumer involvement and selfmanagement, ethics and professionalism, and field experiences. In addition, programs could have areas of specialty practices such as services to the Deaf, addictions, corrections, and so forth.

Programs provided detailed university, program, and curriculum evidence to CUE for initial approval, with yearly updates to maintain Registry status. The yearly updates were valuable in collecting data as to number of students entering the field of rehabilitation, number of students entering graduate programs, employment settings, and strength and expertise of faculty. These data were especially beneficial when planning for undergraduate accreditation began.

There were 12 charter schools approved for the Registry in 1999 (CORE Newsletter, 1999). By 2009 the Registry included 26 programs from 17 different states and two countries.

In July 2011, in the Council for Undergraduate Standards and Accreditation (CUSA), formerly known as CUE, discussed the future of the Registry in light of the CORE Undergraduate Accreditation. At that time it was felt that the Registry fulfilled a viable role in URE for several reasons: (1) the Registry could be helpful as a developmental step for programs seeking future accreditation; (2) the Registry might be more appropriate than accreditation for smaller or newer undergraduate rehabilitation programs, or those programs with less financial capacity; (3) a Registry could be used to provide recognition to institutions that do not offer bachelor's degrees, such as junior colleges; and (4) a Registry might prove to be a more appropriate mechanism for recognizing international programs (CORE Annual Report, 2011). For these reasons, CUSA recommended that the Registry continue even after accreditation was approved by CORE.

In reflection, the CORE Registry on Rehabilitation and Disability Studies was successful on several levels. It provided the framework and foundation for accreditation of URE programs. It established 
curricular content that was shown to be essential to effectively serving PWD. It allowed programs to tailor their programs to the needs of unique geographical areas and local communities. In addition, the Registry provided a venue for understanding the global needs of individuals with disabilities and the training of professionals in different countries. More importantly, the Registry served as a validation of URE and its importance in the career ladder of rehabilitation professional development.

\section{Stage 4-The "Action" Stage}

NCRE supported the idea of an undergraduate Registry and provided financial support to CUE until the Registry became financially stable. Although the Registry eventually grew to 28 programs, the desire for undergraduate accreditation continued to grow.

In 2005, a meeting of undergraduate educators was held by the University of Memphis Institute on Disability. A number of white papers were written at that time, dealing with such topics as undergraduate professional identity, undergraduate curriculum standards, scope of practice, credentialing at the bachelor's level, and development of a code of ethics for bachelor's-level rehabilitation professionals. The work of credentialing and ethical standards development was eventually turned over to NCRE's Council on Rehabilitation and Disability Studies. Due in large part to the productivity of the Memphis meeting, the undergraduate rehabilitation accreditation movement gained greater momentum with CORE, leading to a formal decision in 2008 by the CORE Board to authorize the initiation of a process to develop undergraduate rehabilitation accreditation standards.

\section{Stage 5-The "Maintenance/Relapse/Resurrection" Stage}

In 2009, CUSA sponsored an open meeting for undergraduate rehabilitation educators at Maryville University in St. Louis. The goal was to establish formal accreditation standards that could be used as part of a pilot study of URE accreditation. Wright State University and the University of Wisconsin-Stout agreed to be the first two programs to have site visits, based on the newly proposed accreditation standards.

These site visits provided valuable insights into the accreditation process, allowing CUSA and CORE to refine the process. The next year, CORE opened the accreditation process to all interested programs.

In 2015, CORE announced that it had agreed to merge with the Council for Accreditation of Counseling and Related Educational Programs (CACREP), and that the merger would be completed on July 1, 2017. CACREP took the Standards for URE and created a Registry for URE programs but decided not to engage in the accreditation of URE programs because undergraduate accreditation was not part of their mission or scope of practice.

In the fall of 2016, in part due to the upcoming CORECACREP merger, a national meeting of rehabilitation educators and practitioners was held at the University of Memphis. The purpose was to discuss the future direction of rehabilitation education at various levels. The three-day conference featured a variety of presentations dealing with scholarship, pedagogy, academic standards, ethics, accreditation, and professional credentialing. The meeting was supported by the Rehabilitation Counseling Coalition and UM's Institute on Disability.

At the close of the meeting, a number of attendees joined together in the creation of a special interest group called the International Network of Special Projects in Inclusive Rehabilitation Education and Disability (INSPIRED). This group began by creating a Facebook page, which was designed to serve as an international forum for the sharing of rehabilitation education and disability-related information. The INSPIRED Facebook site currently has 161 members. 
Having gone through all the typical stages of change, from planning to creation to abandonment to future success for URE programs and any other rehabilitation education programs may want to come under this new umbrella for the protection of rehabilitation practice. What appeared to be the decline of undergraduate rehabilitation practice, may in fact become the resurrection of the basic principles that have been driving the field of rehabilitation practice during the last 40 years. Although the profession of rehabilitation will no longer have the protection of RSA, either in grants or in the creation of our standards and practices, URE may be on the verge of creating a more sustainable model of education and practice, which will continue to be innovative, marketable, and resilient in spite of all the significant obstacles that have been faced. The future of rehabilitation practice is again being re-conceptualized, and rehabilitation practice may be creating its own universe for the benefit of PWD and for the good of URE students.

\section{An Optimistic Future: Undergraduate Rehabilitation Accreditation The Commission on Accreditation of Allied Health Education Programs (CAAHEP)}

CAAHEP is a member of the Association of Specialized \& Professional Accreditors (ASPA) and is also recognized by CHEA. C'AAHEP's website says that it "is the largest programmatic accreditor of the health sciences professions. In collaboration with its Committees on Accreditation, CAAHEP reviews and accredits over 2,100 individual education programs in 30 health science occupations" (CAAHEP, 2018a, paragraph 1). The CAAHEP 2015-2018 Strategic Plan lists its mission, purpose and vision, as "to assure quality health professions education to serve the public interest, to assure quality healthcare through excellence in education, and to be the gold standard for programmatic accreditation of allied health" (CAAHEP, 2018b, paragraph 1). These goals are accomplished through a programmatic structure governed by the CAAHEP Commissioners and the Board of Directors, and supported by the CAAHEP Executive Director, CAAHEP staff, and the Committees on Accreditation.

Conceptually, CAAHEP serves as the umbrella accrediting body, and the Committees on Accreditation (CoAs) serve as the spokes of the umbrella. According to CAAHEP, "the CoAs do the day-to-day work of accreditation, reviewing programs' self-studies, coordinating site visits, serving as each program's main contact throughout the review process, and formulating accreditation recommendations which are then considered by the CAAHEP Board of Directors" (CAAHEP, 2018c, paragraph 1). The CoAs represent distinct professions which have been voted as eligible for participation by CAAHEP. The rehabilitationrelated CoAs that utilize CAAHEP as their accrediting body include art therapy, assistive technology, orthotics and prosthetics, and recreational therapy.

\section{Future Steps and Directions}

In February 2018, the INSPIRED task force, with sponsorship from the National Rehabilitation Counseling Association (NRCA), submitted an application to CAAHEP to participate as a unique allied health profession. At the same time, application materials related to development of the Committee on Rehabilitation Accreditation (CoRA) were also submitted. On April 17,2018, the CAAHEP Board of Directors and Commissioners approved the status of the application.

URE accreditation is indeed on a new and promising path. The next step is to more fully formulate the Committee on Rehabilitation Accreditation (CoRA). In partnership with NRCA, CoRA will further develop policies and procedures related to undergraduate rehabilitation accreditation. Plans are to include other rehabilitation partners, associations, and constituents throughout this process. Former undergraduate Commissioners from CORE will also assist in the endeavor. Although the current scope of CoRA is to accredit undergraduate rehabilitation programs, future plans include an application to increase the scope 
to include international programs. This is consistent with the inclusive nature of the rehabilitation profession and will result in additional standards and procedures. It is anticipated, that if approved, this will also result in changes to the original URE standards, thereby strengthening the curriculum to better prepare students to become responsive rehabilitation world citizens.

During the time period in which the task force was working on the application materials, they were also engaged in another vital task. As a result of the CORE/CACREP merger, the existing CORE undergraduate standards were delivered to CACREP, and this resulted in the need for the development of new standards by the INSPIRED task force based on role and function studies and input from URE constituents. New standards were developed with renewed emphasis on personnel preparation, international concepts, and a commitment to return rehabilitation education to its roots and underlying philosophy. At the same time, the task force maintained an overarching goal of moving the rehabilitation profession forward. At the present time, feedback has been received from CSAVR, CRCC, and some undergraduate educators from the Council on Rehabilitation and Disability Studies (NCRE). The next step is to receive additional feedback on the standards from a wider sample of undergraduate rehabilitation stakeholders. After receipt of additional feedback from the "field," the draft standards will be sent to CAAHEP to disseminate for further public comment.

\section{References}

Berven, N.L. (1979). The role and function of the rehabilitation counselor revisited. Rehabilitation Counseling Bulletin, 22, 84-88.

Commission on Accreditation of Allied Health Education Programs (2018a, March 22). What Is CAAHEP? Retrieved from https://www.caahep.org/

Commission on Accreditation of Allied Health Education Programs (2018b, March 22). CAAHEP's Strategic Plan, 2015- 2018. Retrieved from https://www.caahep.org/CAAHEP/ media/CAAHEPDocuments/StrategicPIan.pdf

Commission on Accreditation of Allied Health Education Programs (2018c, March 22). CAAHEP's Different Committees on Accreditation. Retrieved from https://www.caahep.org/ AboutCAAHEP/Committees-on-Accreditation.aspx

Council for Higher Education Accreditation (2010, October 9). Ask before you decide: Accreditation matters. Retrieved from https://www.chea.org/ask-you-decide-accreditationmatters

Council for Higher Education Accreditation (2018, April 2). Information about accreditation. Retrieved from http:// www.chea.org/4DCGI/cms/review.html?Action=CMS_ Document $\&$ DocID $=48 \&$ MenuKey=main

Council on Rehabilitation Education. (1998). Application and review process: Registry of undergraduate programs in rehabilitation and disability studies. Rolling Meadows, IL: Author.

Council on Rehabilitation Education. (2011). Annual Report to CORE from the Commission on Undergraduate Standards and Accreditation. Rolling Meadows, IL. Author.

Department of Education. (2018, April 11). The Rehabilitation Act of 1973, as amended. Retrieved from https://www2. ed.gov/policy/speced/leg/rehab/rehabilitation-act-of1973-amended-by-wioa.pdf

Duncan, J.C. (2008). The purpose of undergraduate rehabilitation education: Implications for curriculum development (Doctoral dissertation). Retrieved from https://etd. auburn, edu/handle/10415/1251 
Feinberg, L., Sundblad, L., \& Glick, L. (1974). Education fo r rehabilitation services: Planning undergraduate curriculum. Syracuse, NY: Syracuse University School of Education, Division of Special Education and Rehabilitation.

Gandy, G.L. (1987). Toward a clearer definition of undergraduate rehabilitation education. Richmond, VA: Commonwealth Papers, Center for Public Affairs, Virginia Commonwealth University.

Gandy, G.L., \& Martin, D.E. (1985). Undergraduate rehabilitation Education: A humanistic approach. Rehabilitation Literature, 46( 11-12), 321-324.

Herbert, J.T., Barrett, K., Evenson, T., \& Jacob, C.J. (2010). Work roles and functions of undergraduate rehabilitation services alumni: A pilot study. Rehabilitation Education, 24, 149-166.

Hylbert, K.W. (1963). Experiment at Penn State: Bachelor of rehabilitation. Journal of Rehabilitation, 29(2), 23-24.

Hylbert, K.W. (1972). Undergraduate education for counselors. Counselor Education and Supervision, II, 284-292.

Hylbert. K.W. \& Kelz, J. W. (1972). A bachelor's in rehabilitation. The Journal of Applied Rehabilitation Counseling, 3(2), 44-52.

Jacques, M. (1972). Rehabilitation counseling and support personnel. Rehabilitation Counseling Bulletin, $15,160-169$.

Leahy M., Chan, F., \& Saunders, J. (2003). Job functions and knowledge requirements of certified rehabilitation counselors in the 21st century. Rehabilitation Counseling Bulletin, 46, 66-81.

McAllan, L., \& Sales, A. (2000). Career ladder: A practical model for undergraduate education. Rehabilitation Education, 14( 1), 77-87.

Muzzio, T. (2000). Undergraduate rehabilitation education: The need for graduates from the perspective of the public rehabilitation program. Rehabilitation Education, 14, 89-95.

Perry D. C. (2000). Understanding and Appreciating Undergraduate Rehabilitation Education. Rehabilitation Education, 14, 3-11.

Redkey, H. (1971). Undergraduate curriculum: A success. Journal of Rehabilitation, 37(6), 15-17.

Schroeder,F. (1998). RSA Commissioner'sMemorandum. Retrieved from https://www2.ed.gov/students/college/aid/rehab/ cspdcm.doc

Stegar J.M. (1974). A multidisciplinary model for undergraduate education in rehabilitation. Rehabilitation Counseling Bulletin, 18, 18-22.

Williamson, C.J., Evenson, T.L., \& Perry, D.C. (1996). Worker roles and competencies for baccalaureate service providers: A national survey. Rehabilitation Education, 10, 305-318. 